\title{
IN THINGS WE TRUST Hybridity and the Borders of Categorization in Archaeology
}

\author{
Caroline Petersson
}

The aim of the article is to question essentialist constructions of archaeological cultures with the help of Homi K. Bhabha's concept of hybridity. Using house urns found in central and northern Europe as a case study, Bhabha's hybridity concept is presented and discussed as an alternative to traditional archaeological concepts of cultural interpretation. Hybridity, which is also a key concept in postcolonial theory, offers an alternative key to the interpretation of culture and suggests that no culture should be seen as static and homogeneous. The common understanding of house urns is therefore informed and challenged by the concept of hybridity, its alternative construction of culture and alternative ways to understand artefacts. Inspired by the concept of hybridity, I argue that house urns deserve much broader interpretations than as mere manifestations of cultural difference or cultural belonging.

Keywords: Hybridity, house urns, postcolonial theory, categorization, materiality

\section{LEVEL AND REBUILD}

In this article I propose that archaeology would benefit from a discussion that problematizes the categories in which we order culture as well as material culture in prehistory. The concept of bybridity, borrowed from Homi K. Bhabha, will be presented as a tool to understand the construction of culture, and hence it will serve as an alternative instru- 
ment of interpretation. By using Bronze Age house urns as a case study, I will try to show how we can broaden our interpretation of archaeological culture(s) with the help of the concept of hybridity.

Stories of house urns have commonly focused on their origin. And the desire to search for an origin is not at all limited to house urns; on the contrary, it is a common approach to almost all archaeological material. When house urns are mentioned in archaeological literature, they are often accompanied by questions such as, 'Are the Scandinavian house urns a result of the hut urns from the Italian peninsula or is the "mother urn" to be found on the island of Gotland?' The cultural belonging of house urns is also a key question. In her dissertation House Urns: Study of a Late Bronze Age Trans-cultural Phenomenon (2007), Serena Sabatini writes that her study "seeks to avoid an idea of culture and cultural identity as a compact or static entity" (2007:49). Sabatini's approach is a recent substantial contribution to the house urn discussion, and therefore I will often use her study as a point of departure for my discussion. My discussion should not, however, be read as a polemic critique of Sabatini, but rather as a suggestion for alternative ways to understand culture in archaeology. The article proposes that archaeology would benefit from a discussion that problematizes the categories in which we order culture as well as material culture in prehistory. The concept of hybridity will be presented as a tool to understand the construction of culture. By using house urns as a case study, I will try to show how we can broaden our interpretation of archaeological culture(s) with the help of the concept of hybridity. In other words, the traditional interpretation of archaeological culture will here be represented by the interpretations of house urns from eastern and northern Europe. By focusing on the structure of archaeological thought rather than on the house urn as a specific object, I hope to make this discussion equally applicable to other archaeological objects besides house urns.

I found that I was an object in the midst of other objects

(Fanon I967)

\section{Level}

Discussions of house urns are, as mentioned, often driven by a desire to find the location of their first usage. The house urns first appeared in archaeological literature in the mid-I9th century (Soterup I845), soon after they were first found. In the late I9th century discussions focused on connections between house urns found in Germany and in Italy, and at the turn of the 2 oth century it was proposed that the house urn phenomenon belonged to a time span from the Neolithic to the Roman era 
(Sabatini 2007:Ioff). Harald Hansson (I927) argued that the Scandinavian house urns were the oldest and should not be seen as a result of diffusion from southern Europe. Around 1950-54 the house urn origin question was re-examined and it was now proposed that the original birthplace of both the house urns and the similar hut urns was somewhere along the river Danube (Sabatini 2007:I4).

In the early second part of the 2oth century new house urns were discovered in Scandinavia, and these finds rekindled the interest in house urns among Swedish scholars. Greta Arwidsson (1952) highlighted the relation between house urns and ship-shaped stone settings on the island of Gotland in her presentation of the urn from Ansarve. According to her, both urns and stone settings suggest a specific ideological connection with the rest of the continent. In accordance with Arwidsson, Richard Bradley says it is highly probable that there were contacts between the two areas in which house urns are found (2005:50). Andreas Oldeberg (1958) argued that the house urns in Scandinavia were local variations of an original house urn shape from central Germany, while Berta Stjernquist brought the other Scandinavian house urns, apart from those found on Gotland, into the discussion and proposed a cultural and chronological contextualization of the whole house urn phenomenon (Stjernquist 196I).

\section{Rebuild}

This article aims to break with the traditional focus on origin and first usage in the interpretation of house urns. The reason is that the search for an original house urn tradition has in many cases resulted in an unconsidered designation of the people who used house urns as a single homogeneous group. As a result, archaeology has created a group of prehistoric "house urn people" that only exists as an opposition to other homogeneous groups, groups that did not use house urns. These groups are commonly expressed and understood as cultures, which in one way or another are different from each other.

In order to reach beyond the frames of culture, which is easier said than done, I will use the concept of hybridity to help disorder our notion of fixed borders and categories. Hybridity should here be understood as an ongoing process that does not care about origin or end. Thus the use of hybridity entails that there are no homogeneous cultures, communities or nations. On the contrary, hybridity could be understood as a river, a flow of water that is impossible to freeze into essential categories like "a culture" or "national belonging". Homi Bhabha says that we have to understand all cultural statements and systems as constructed in an ambivalent space of enunciation. In this space where cultural statements 
are expressed we might find an answer to why hierarchical claims to the inherent originality of cultures are unjustifiable (I994:54f). In accordance with Robert Young (1995:27) I mean that there is no single or absolute way to use the concept of hybridity, but that there are aspects of the concept that cannot be neglected. Matthew Liebmann says that the concept of hybridity helps archaeologists to reach beyond the tradition of binary opposition, because it opens a space where the confusing, ambiguous and contradictory modes of material culture can be examined (2008:5). In my own opinion hybridity forces us to evaluate our most fundamental ideas of culture. It makes us question the binaries we have created and the border we expect to find between them. Hybridity shows us that our interpretation of archaeological materiality can and should go much deeper than the question of origin. By applying hybridity, as a process, to the interpretation of house urns, the traditional interest in origin, essential cultural groups and first area of use immediately stands out as quite limited and problematic. So hybridity can indeed contribute with vital questions and critique for archaeology.

The importance of hybridity as an analytical concept that challenges claims of originality and essence has long been more or less neglected in archaeology, along with postcolonial theory in general. The point of departure for archaeological narratives is normally a generalized fiction of homogeneous cultures or ethnic groups which break fundamentally with the arguments for hybridity (Fahlander 2007:I9). As a result, postcolonial theory and its resulting dialogues about the discursive responsibility of structures and issues related to colonialism and imperialism have been very rare in archaeology (van Dommelen 2006:I09). But the interest in postcolonial theory has been growing in archaeology over the last decade. Recent texts show how the values of postcolonial theory can challenge archaeological truths (Gosden 200I; Liebmann \& Rizvi 2008; Lydon \& Rizvi 20I0; Patterson 2008; van Dommelen 20II) and how postcolonial theory can be of great interest in the interpretation of material culture (Andreeff 2007; Harrison 2002; Lightford et al. 1998; Stoler I989; to mention a few).

\section{Hybridity in the house}

The term "house urn" was invented in the mid-Igth century. The house urns are also often discussed as northern and/or southern house urns. The current most accepted interpretation is that southern house urns, i.e. those found in present-day northern Italy, are representations of dwellings whereas the northern house urns, found mostly in present-day Germany, Poland and Denmark, represent storehouses (Bradley 2002:373). 
Serena Sabatini has suggested that house urns had a particular value as markers of identity in a tradition containing both hut urns and face urns. The house urns are assumed to mark a special group in society, reflecting social status or gender (Bradley 2002:372), and as such they are a fundamental component of culture (Sabatini 2007:I68). This approach to house urns still highlights them as essentially different in a cultural tradition which also includes face urns and hut urns. This "cultural tradition of the urns" is predetermined as something different from other cultures, or cultural traditions, and hence an interpretation of this kind loses itself in the boundaries of categorization and the construction of culture. In my opinion this approach could easily be widened with the concept of hybridity. When faced with hybridity, the word culture as we commonly use it, as a steppingstone on the way to questions, must be questioned in its essence. In Sabatini's text, the interpretation reveals its own limits when burials are discussed as being reflections of oppositions to the common tradition in details that do not leave durable traces (Sabatini 2007:I68). To me this demonstrates how difficult it is to step away from the well-trodden manner in which we order and narrate prehistory. Sabatini, along with other authors, has made many successful efforts to problematize the narratives of house urns, and therefore it is frustrating to see how the categorization of culture is so deeply imbedded in our modes of interpretation that it slips through Sabatini's fingers without her even reflecting on it.

Instead of discussing the exact locations of expected borders between essential cultures, alternative explanations could free our interpretations from this never-ending struggle to frame culture in static and easy-to-read units.

\section{BRIDGING THE BORDERS OF CATEGORIZATION}

The application of the concept of hybridity to the traditional discussion of house urns demonstrates that the categories we use in archaeology may work to control our imagination more than they help to interpret materialities of the past. The idea of a single path of social evolution in which human populations move from simple to more complex societies is still affecting archaeological interpretation. This is exemplified by assumptions that the progress of civilization unavoidably develops from "primitive" hunter-gatherers to civilized state-level societies (Lydon \& Rizvi 20I0:24). In Stuart Hall's discussion about cultural identity he argues, contrary to such simplistic images, that identity should be understood as a production which is never complete. Identity is always in 
process and always created and recreated in acts of representation. Hall says that such a view on identity problematizes the authority and authenticity of the term cultural identity (Hall I990:222).

On a similar note I would like to show how hybridity can be used in discussions of culture in archaeology. A basic foundation for the argument of this article is that cultures are constructed, and thereby we must also acknowledge structures within that which we call culture. This means that in the constructions of cultures there are subcategories such as gender or class. Subcategories are constructed in the same way as culture and they can be understood as bricks in the larger construction of society. If we want to understand the construction of culture, hybridity helps us to see that culture is not only constructed but also constantly recreated, or reconstructed. Stuart Hall writes that cultural identity is not an essence but a positioning, and hence "there is always a politics of identity, a politics of position, which has no absolute guarantee in an unproblematic, transcendental law of origin" (Hall I990:226). If we agree with Hall that there is no spirit or essence defining the inside and outside of culture, then essential culture is nowhere to be found. However, culture is a label which often appears on materiality; the word culture is attached to materiality defining the Pitted Ware culture and the Funnelbeaker culture, for example. It puts the interpretation in a locked space where, when not problematized; materiality equals culture.

To understand our wish to label materiality we must know that the two theoretical paradigms that dominated scientific thought during the late I9th century were evolutionism and the joining of nation-states. Evolutionism was the foundation for a naturalistic approach to human diversity while the alliances of nation-states reflected current theories of culture and society (Fabian 2000:I7f). Fabian says that natural history is based on the belief that knowledge is produced by observing nature. Hence knowledge of the human cultural and social organization only becomes scientifically correct when it follows the same scientific rules as are used when observing nature (Fabian 2000:I8I). Bhabha says that historicism proposes a linear reproduction of events that most commonly represent the development of a nation or a national culture as an "empirical sociological category or a holistic cultural entity" (Bhabha I994:20I). In archaeology the categorizing and ordering of objects is key, and the typological method has become a sort of common sense in the archaeological discipline. The linear way of thinking about time, with the three-age system as a strong metaphor both inside and outside of archaeology, works as an important tool for archaeological categorization. This categorization also works as a means to explain the connection between time and cultural distance as two measurable units 
in the study of man. In the I9th century this meant that through the three-age system, which we still use in archaeology, all people on earth, whether living or dead, could be placed somewhere along the teleological line (Jakobsson \& Källén 20IO:I54). The archaeological artefacts, the things in which we trust, were used as measurements of technology while at the same time determining where on the scale of development to place living people in light of their technological achievements. In the same way that culture is constructed and reconstructed, archaeologists reconstruct the structures of our own present or ideal society since we, the archaeologists, are part of society. There is no fundamental difference between the act of categorizing objects into a special time-frame and the creation and maintenance of ideas of homogeneous cultures.

\section{THE DIFFERENCE OF THE SAME}

Homi Bhabha's concept of hybridity is complex in itself and at times it is hard to see a difference between his usage of hybridity and hybrid. The definition of hybridity as a process and hybrid as a product might help to single them out. A hybrid, for instance, can be seen as the product of two different elements; the music style jungle is the hybrid of reggae and house music, for example. Hybridity, on the other hand, is the process underlying all interactions between people, the process of movement which can result in objects as the expression of the interaction. Hybridity is in movement but has no particular speed or direction. The key is to understand the concept as a process, a process underlying all interactions between people, the process of movement which can result in objects as the expression of the interaction. In my reading of Bhabha, I understand hybridity as a flowing river (figure I). Cultures and material culture can be seen as floes of ice that follow, deform and disappear in the constant, unpredictable movement of the river. One ice floe might look as if it has a specific form at one moment, as in the photo of figure I. However, the stability is only an illusion because of the constant movement of the swirling water below (hybridity). Hence a piece of archaeological material can in our eyes be understood as representing one culture, but just as the ice floes are drifting, melting, reforming and bursting, so too are societies or culture. In other words, the constructed culture has an expression, but both culture and its expressions are in constant movement and must be understood as much more complex than a homogeneous group of people making the same objects for hundreds or thousands of years just to identify themselves as the same or as different from others. 


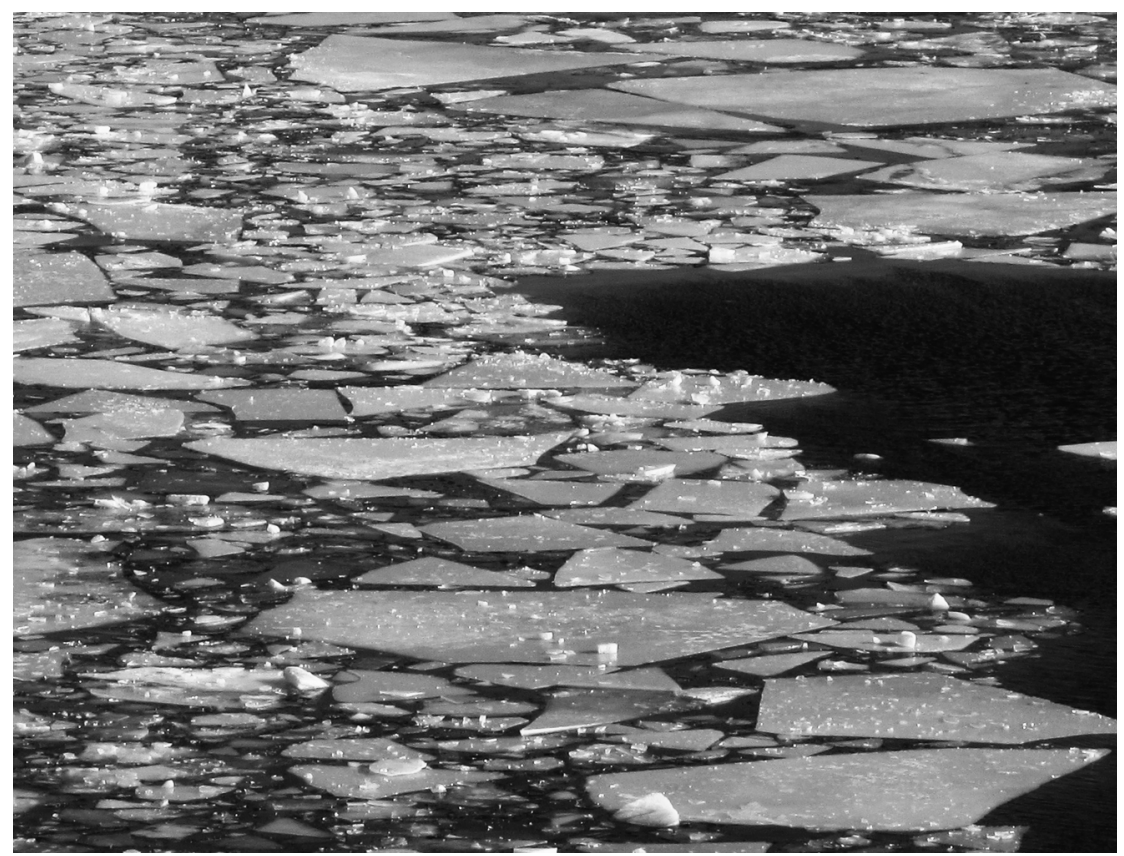

Figure I. Floes of ice on the moving water as an illustration of culture and hybridity. Photo by Gustav Gonelius Stenvall from the bridge Västerbron in Stockholm, January 20 II.

By using the concept of hybridity, the problematic binary structure that defines our idea of essential cultures can be questioned and even dismissed. When discussing house urns in relation to hybridity, the dialectic character of the urns must be recognized as moments of expression, which could indeed be indications of cultural encounters. However, these encounters should not be understood as clashes between different essential cultures, but as meetings, interactions, and transports of fragments of ideas which through a constant swirling process made the creation of house urns possible.

\section{Neither the one nor the other}

Hybridity in common sense often refers to the complex transcultural forms produced through colonization that cannot be neatly classified into a single cultural or ethnic category. The concept posits that the interaction of social groups creates new cultural forms that are neither wholly immigrant nor wholly indigenous but are interdependent and mutually constituting (Liebmann 2008:82f). But according to Bhabha, hybridity should not be misunderstood as a simple merging of old and new elements into a "crossbreed" of ideology or practice (Fahlander 
2007:19) as in the example of a hybrid above. Instead it should be understood as encounters that actually result in something new and substantially different than mere corporations of new and old elements (Fahlander 2007:22).

Ania Loomba explains hybridity as a concept that illuminates our use of binaries and our ideas of refinement (2005:175). Applying hybridity to archaeological materiality is to realize that a black and white photo actually is an image of something more colorful. Hence, when it comes to the construction of culture, hybridity works as a bridge between the binaries that create cultural difference in a traditional modern discourse. In other words, the understanding of culture as existing in opposition to Other cultures is seriously challenged when applying the concept of hybridity to the construction of culture. According to Bhabha, culture is constructed in two ways. Cultural diversity is the recognition of pre-given and dynamic cultural attributes; it is the point from which ideas of multiculturalism, cultural exchange and the culture of humanity develop. Cultural difference reflects the problem of the ambivalence of cultural authority. Cultural difference attempts to dominate in the name of a cultural supremacy. Cultural supremacy, however, can only be produced in the moment of differentiation. In other words, cultural difference only exists in the very production of culture and the meaning held in the name of that culture (Bhabha 1994:50). The location of culture can thus be found everywhere and nowhere. It can be found in any place where the production and reproduction of culture are structured, articulated and expressed, and it can be found nowhere since there is no homogeneous essential culture to be found.

Serena Sabatini expresses doubt as to how much we can say about cultural identity solely on the basis of an archaeological material. She says that as far as the available documentation of house urns goes, it indicate the presence of groups and/or individuals spread over a large territory and a vast period of time. House urns are found in a large area and that, according to Sabatini, implies cultural heterogeneity. And when Sabatini sees heterogeneity among the house urns, she also sees boundaries. She writes (Sabatini 2007:5I):

The size of their [house urn] distribution implies cultural heterogeneity and, thus, boundaries; different natural and socio-cultural conditions and limits between the various groups inhabiting the area obviously existed.

To me such limits are not obvious, and the archaeological material of house urns as evidence fails to convince me. If we are talking about limits and boundaries in prehistory we have to ask ourselves how, when and why these limits make themselves visible to us and attract our attention. 


\section{REPRESENTATIVE CLAY}

House urns have been found in various parts of the north European continent. So far most of them have been found in central Germany, but scattered clusters are known from all over northern Europe. In view of the fact that the house urns often appear in clusters, they have, as mentioned above, often been understood as intentionally used by particular groups or grouped individuals, in specific zones. Serena Sabatini argues that in none of the cemeteries where the house urns were found do they represent the usual tradition; instead they seem to be exceptional ( $\mathrm{Sa}$ batini 2007:2 If). This could be an indication of the diversity in a society, although this is not a major point made by Sabatini. This is where hybridity can offer us an alternative interpretation. Unlike the more common interpretation of house urns - and other archaeological material - that makes categorization based on the recognition of "belonging" or "not belonging" into a context, hybridity is the displacement of value from recognition to difference. Hybridity thus makes the dominant discourse lose its representative value, and it helps the marginal and discriminated to question the images of authority (Bhabha I994:I62). This translates to archaeology if we understand that the recognition Bhabha refers to is the recognition of belonging or not belonging which categorizes the artefact and makes archaeological material stable. When archaeological objects do not easily fit our familiar idea of prehistory, our ambivalence often results in an eagerness to categorize the objects simply to make them stable again.

By bringing Bhabha's concept of hybridity into the discussion of archaeological material in general and into the discussion of house urns in particular, I also want to challenge the idea of human groups as natural opposites, as in the common model of "the people with house urns versus the people without". Such an idea of human groups as created by natural opposition is a legacy from the early days of our discipline. To challenge such ideas we need to be clearer and more specific about what we think we can see in our material when we claim to identify groups in opposition during prehistory. The making of an archaeological culture and its material indicators must in other words be deconstructed in order to understand culture in terms of hybridity. Because of the common fiction of cultures as static we apply certain scenarios to the encounters between them. Fredrik Fahlander writes that since culture-contacts in prehistory have traditionally been imagined as encounters between homogeneous collectives, the scenarios emerging in the encounters have been understood as processes involving aggressive assaults, friendly exchange or colonial-style acculturation (Fahlander 2007:35). This ten- 
dency to form interpretations of opposing groups is also present in the discussions of house urns (Sabatini 2007:156). My point is not to claim that exchange did not occur; on the contrary, I mean that if we want to break with the images of exclusive, closed-off groups of humans - images that stem from the I9th century - such a break must involve a disorder in our common interpretations of culture.

Bhabha uses the term "the third space of enunciation" to explain the structure of meaning and reference as an ambivalent process. The third space of enunciation destroys the mirror of representation in which cultural knowledge usually is revealed as an integrated, open, expanding code (Bhabha 1994:54). This third space is a metaphor for the unclear virtual field that emerges when two or more individuals interact, and thus a culture-contact must be understood as a series of encounters between individuals in an unclear virtual field rather than a clash between totalities based on class, ethnicity or religion (Fahlander 2007:22f). Leif Karlenby uses the third space of enunciation when discussing ethnicity and material culture in connection with pottery from the Bronze Age. $\mathrm{He}$ argues that ethnicity usually progresses as a strategy of a group in meetings with other groups and that the third space is where new and original situations occur. It is not a mixture or a unification of the two, but a completely new state of affairs (Karlenby 20I0:I48).

\section{A house is a house is a house?}

When discussing house urns it is crucial to reflect on the interpretations of their symbolism. If a group of people using house urns can be called a culture, what did the house urns represent? The most common interpretation of house urns as symbols is that they represent models of dwellings or storehouses. But the connection between dwellings, graves and ancestors is not something exclusive for house urns; it is in fact a connection that can be applied to all urns used in burials (Kaliff 1997:7I). Richard Bradley proposes that the burned bones, the remains of the dead which are usually found in house urns, were associated with the crops that were harvested year after year. House urns can thereby be understood as metaphors for agricultural reproduction, which had an important role in late prehistoric Europe (2002:375). Bradley also interprets the house urns as direct representations of storehouses, based on the appearance of round house urns with their door placed high up on the wall (Bradley 2005:I00). Berta Stjernquist, on the other hand, says that while some of the house urns might have an architecture similar to storehouses, the simple shape of storehouses has a close similarity to traditional pottery vessels as well (I96I:55). Stjernquist proposes that house urns should be understood as symbols of dwellings, some more 
detailed than others, and under such circumstances house urns cannot be expected to infer one style of architecture from another, even if knowledge of specific details from other regions may have influenced individual types of house urns (Stjernquist 1961:57).

Homi Bhabha argues that repeatability is production in an act of enunciation, a reaction to something Other, a difference that is perhaps a bit uncanny (Bhabha I994:I87). If we take the production of house urns into this hybrid third space, the repetitive production of urns always repeats something other through its own repetition. In one sense Stjernquist's argument that house urns should be understood as symbols of dwellings - symbols that cannot be translated to archaeological explanations of a chain of development from one original house urn tradition to other more fulfilled forms - touches upon Bhabha's ideas of cultural hybridity. It is a discussion that goes outside of the traditional focus on origin. On the other hand Stjernquist is still talking of house urns as a single category, which forces them and the people who used them into a relationship of similarity and cultural belonging.

Fredrik Fahlander writes that a description in terms of social diversity implies that misunderstandings and uncertainties not only occur between individuals of different traditions but also characterize many interactions between individuals within the same collective (2007:23). These misunderstandings are connected to acts of enunciation. Even if a misunderstanding is not revealed to be a misunderstanding, the difference that is a bit uncanny has demanded place. To understand house urns, or any archaeological material, it is crucial to be aware of the diversity in collectives and to know that categories, whatever they represent, are representations of something. Peter van Dommelen writes that the hybridity concept provides a conceptual tool when hybridity is connected to material culture and understood as the process underlying the "cultural mixture", which is the effect of the practice of mixed origins (van Dommelen 2006:II9). In one sense van Dommelen's argument for the use of hybridity takes the edge off the concept as it is used in this article. The mix of origins that van Dommelen refers to must be understood in terms of temporality - if, now, we want to search for origins - and hybridity is then the underlying movement which makes material representations possible through encounters, acts and misunderstandings in the third space of enunciation. Because of the heterogeneous character of societies such encounters can be found everywhere, not only between different cultures, or between clear categories within the culture, such as we are used to picturing it. Even encounters with something or someone familiar are encounters and can result in something different, something outstanding. 


\section{IN THINGS WE TRUST}

Crucial to many archaeological discussions about house urns is the question of their location, or their spread. Most of the find locations for house urns have a connection to water, either open water or rivers. The interpretations that have followed from that observation are thus that the house urns were used by single, or groups of, households near the Baltic Sea or along some of the major north European rivers (Sabatini 2007:25; see also Bradley et al. 2010:94). Following Bhabha's definition of culture and hybridity, my suggestion is that the house urns sites do not necessarily offer any clues to the identification of a people who used them. In other words, the locations in themselves do not represent the area of a specific culture that used house urns. It is not the location that holds the key to why house urns were used, as this location could have been "everywhere". The act of enunciation could have occurred at the places where the house urns were found, but it is also possible that the expression "travelled" in the meetings between people. As the borders of categorization have been bridged, expressions of materiality can be understood as moments of expression in a heterogeneous collective, where expressions of cultural belonging appear, reform and disappear as lightly as ice floes on the river. But the bridges do not only make it possible to understand the house urn enunciation in a large scale but also in a small scale, from person to person. The use of house urns repeats actions which existed in the collective. However, the repetition and the act of enunciation made difference possible. The difference is revealed in the variation of house urns (which by archaeologists have been forced into essential typological categories such as "door urns", "oval bases", "open roofs", etc.). The variation, the heterogeneity, among the house urns themselves might explain a more complex situation than simple exchange, violent conquests, or friendly trade. House urns are found in several types of graves, in cairns, mounds, ship-shaped stone settings and flat-ground burials, burial forms that were used in the "common tradition" as well. The space of hybridity, which enabled the enunciation of house urns, could be explained as a series of encounters between people in ambivalent processes. These processes could very well have taken place without declarations of cultural difference; and therefore house urns do not have to be manifestations of cultural difference or cultural belonging.

Our common way of thinking in binaries may make this difficult to grasp. I would like to propose that one way of understanding the house urns is to see them as parts of a larger web of interaction. The discussion about the origin of house urns should thereby have reached the end 
of the road. Is it really justifiable to freeze a movement, a process, on behalf of one's own narrow vision? And is/are "culture/s" in our contemporary society willing to be forced into the same categorization? To reach beyond the routine categorization that continues to flourish in archaeology, we must open for a discussion that can seriously challenge the traditional categorization of culture itself. If the interpretations of the archaeological material continue to rest only on the modern Western world's insistence on categorizing homogeneous cultures along an imagined vertical progression of time, our interpretations will only be able to reproduce the same conclusions.

I embrace the world! I am the world!

(Fanon 1967)

Caroline Petersson Folkskolegatan 22 B, I I7 35 Stockholm

\section{REFERENCES}

Andreeff, A. 2007. Gotlandic Picture Stones, Hybridity and Material Culture. In: Cornell, P. \& Fahlander, F. (Eds). Encounters, Materialities, Confrontations: Archaeologies of Social Space and Interaction. Pp. 242-258. Newcastle: Cambridge Scholars Press.

Arwidsson, G. 1952. Husurnan från Ansarvde i Tofta. Gotländskt Arkiv. Pp. 16-37.

Bhabha, H. K. 1994. The Location of Culture. London: Routledge.

Bradley, R. 2002. Death and the Regeneration of Life: A New Interpretation of House Urns in Northern Europe. Antiguity. Vol. 76. Pp. 372-377.

Bradley, R. 2005. Ritual and Domestic Life in Prehistoric Europe. London: Routledge.

Bradley, R. Skoglund, P. \& Wehlin, J. 20Io. Imaginary Vessels in the Late Bronze Age of Gotland and South Scandinavia: Ship Settings, Rock Carvings and Decorated Metalwork. Current Swedish Archaeology. Vol. I8. Pp. 79-103

Fabian, J. 2000. Out of our Minds: Reason and Madness in the Exploration of Central Africa: The Ad. E. Jensen Lectures at the Frobenius Institut, University of Frankfurt. Berkeley: University of California Press.

Fahlander, F. 2007. Third Space Encounters: Hybridity, Mimicry and Interstitial Practice. In: Cornell, P. \& Fahlander, F. (Eds). Encounters, Materialities, Confrontations: Archaeologies of Social Space and Interaction. Pp. I5-4I. Newcastle: Cambridge Scholars Press.

Fanon, F. 1967. Black Skin, White Masks. New York: Grove Press.

Gosden, C. 200I. Postcolonial Archaeology: Issues of Culture, Identity and Knowledge. In: Hodder, I. (Ed.). Archaeological Theory Today. Pp. 24I-26I. Cambridge: Polity.

Hall, S. I990. Cultural Identity and Diaspora. In: Rutherford, J. (Ed.). Identity: Community, Culture, Difference. Pp. 222-237. London: Lawrence \& Wishart. 
Hansson, H. 1927. Gotlands bronsålder. Kungl. Vitterhets Historiska och Antikvitets Akademiens Handlingar 37, I.

Harrison, R. 2002. Archaeology and the Colonial Encounter: Kimberly Spearpoints, Cultural Identity and Masculinity in the North of Australia. Journal of Social Archaeology. Vol. 2. Pp. 352-377.

Jakobsson, M. \& Källén, A. 2009. A Hobbling Marriage: On the Relationship Between the Collections and the Societal Mission of the Museum of National Antiquities in Stockholm. Current Swedish Archaeology. Vol. I7. Pp. I 5 I-164.

Kaliff, A. I997. Grav och kultplats: eskatologiska föreställningar under yngre bronsålder och äldre järnålder $i$ Östergötland. Dissertation. Uppsala: Uppsala University.

Karlenby, L. 20Io. Pottery in the Well - The Significance of Late Neolithic/Early Bronze Age Decorated Pottery in East Sweden. In: Martinsson-Wallin, H. (Ed.). Baltic Prehistoric Interactions and Transformations: the Neolithic to the Bronze Age. Pp. I4 I-I 52. Visby: Gotland University Press.

Liebmann, M. \& Rizvi, U. Z. 2008. Archaeology and the Postcolonial Critique. Lanham, MD: AltaMira Press.

Libmann, M. 2008. Postcolonial Cultural Affiliation: Essentialism, Hybridity, and NAGPRA. In: Liebmann, M. \& Rizvi, U. Z. (Eds). Archaeology and the Postcolonial Critique. Pp. 73-90. Lanham, MD: AltaMira Press.

Lightfoot, K.G., Martinez, A. \& Schiff, A.M. I998. Daily Practice and Material Culture in Pluralistic Social Settings. American Antiguity. Vol. 63. Pp. I99-222.

Loomba, Ania. 2005. Kolonialism/Postkolonialism: En introduktion till ett forskningsfält. Stockholm: Tankekraft.

Lydon, J. \& Rizvi, U. Z. 20ıо. Handbook of Postcolonial Archaeology. Walnut Creek: Left Coast Press.

Oldeberg, A. 1958. Några Gotländska husurnor. Fornvännen. Vol. 2. Pp. I-I6.

Pattersson, T. C. 2008. A Brief History of Postcolonial Theory and Implications for Archaeology. In: Liebmann, M. \& Rizvi, U. Z. (Eds). Archaeology and the Postcolonial Critique. Pp. 2I-34. Lanham, MD: AltaMira Press.

Sabatini, S. 2007. House Urns: Study of a Late Bronze Age Trans-cultural Phenomenon. Dissertation, Department of Archaeology. Gothenburg: University of Gothenburg.

Soterup, J.B . I845. Udsigt over Urner, Gravar og jordfundne Kar fra Nordens Hedenold. Annaler for Nordisk Oldkyndlighed. Pp. 317-367.

Stjernquist, B. 196r. Simris. 2, Bronze Age Problems in the Light of the Simris Excavation. Lund.

Stoler, G.J. 1989. Rethinking Colonial Categories: European Communities and the Bounderies of Rule. Comparative Studies in Society and History. Vol 3I. Pp. I34I6I.

Young, R. 1995. Colonial Desire. London: Routledge.

Van Dommelen, P. 2006. Colonial Matters, Material Culture and Postcolonial Theory in Colonial Situations. In: Tilley, C. (Ed.). Handbook of Material Culture. Pp. IO4-I24. London: SAGE.

Van Dommelen, P. 20I r. Postcolonial Archaeologies Between Discourse and Practice. World Archaeology. Vol. 43(I). Pp. I-6. 